\title{
Synchrony between Ovarian Function \& Sleep in Polycystic Ovary Syndrome Patients
}

\author{
Farideh Zafari Zangeneh ${ }^{1 *}$, Mohammad Mehdi Naghizadeh2, \\ Alireza Abdollahi' ${ }^{3}$, Maryam Bagheri' ${ }^{1}$ \\ ${ }^{1}$ Reproductive Health Research Center, Tehran University of Medical Sciences, Tehran, Iran \\ ${ }^{2}$ Department of Community Medicine, Medical Faculty, Fasa University of Medical Sciences, Fasa, Iran \\ ${ }^{3}$ Pathology Laboratory, Vali-e-Asr Hospital, Tehran University of Medical Sciences, Tehran, Iran \\ Email: ${ }^{\text {zangeneh14@gmail.com }}$
}

Received 17 June 2014; revised 14 July 2014; accepted 11 August 2014

Copyright (C) 2014 by authors and Scientific Research Publishing Inc.

This work is licensed under the Creative Commons Attribution International License (CC BY).

http://creativecommons.org/licenses/by/4.0/

c) (i) Dpen Access

\section{Abstract}

Polycystic ovary syndrome (PCOS) is a complex, multifaceted, heterogeneous disorder, affecting $\mathbf{4 \%}$ to $18 \%$ of reproductive-aged women and is associated with reproductive, metabolic and psychological dysfunction. In this study we determined the relationship between the time to sleep and serum levels of neurohormones in polycystic ovary syndrome (PCOS). Totally 77 PCO patients (case group) and 97 non-PCOS infertile women (control subjects) participated in this study between February 2012 and February 2013. A PSQI sleep questionnaire was completed by each patient in both groups. PSQI sleep questionnaire score and serum concentration of adrenaline, noradrenaline, melatonin, $\beta$-endorphin, cortisol and progesterone were compared in two groups. The results of the study indicate that serum levels of melatonin and $\beta$-endorphin were lower in women with PCOS. Serum level of stress hormones, adrenaline and noradrenaline were significantly correlated with patients' sleep time in study group. Serum level of adrenaline in control group was significantly lower in women who wake up earlier in the morning. All hormones except for cortisol had no significant correlation with PSQI global score in both groups and also the people who sleep less than 8 hours had lower cortisol level. These data showed that changes in cortisol in PCO women were due to damage of disturbed sleep at night. Our preliminary work provided this study with new insight into the interactions between sleep-wake cycles in PCO women with specific sleep patterns.

\section{Keywords}

Polycystic Ovary Syndrome (PCOS), Sleep, Stress Hormone, $\beta$-Endorphin, Melatonin

\footnotetext{
${ }^{*}$ Corresponding author.
} 


\section{Introduction}

Polycystic ovary syndrome (PCOS), the most common female endocrine disorder, is a complex and heterogenic disease with unknown etiology. PCOS is characterized by reproductive disturbances including chronic anovulation, hyperandrogenism and polycystic ovaries [1]. Its prevalence among infertile women is $15 \%-20 \%$ [2]. Although menstrual irregularities in adolescent girls are often attributed to an immature Hypothalamus-Pituitary-Gonadal (HPG) axis [3], many adolescents with persistent menstrual abnormalities may raise concern of PCOS. Women with ovulatory menstrual cycles have a circadian rhythm superimposed on the menstrual-associated rhythm; in turn, menstrual events affect the circadian rhythm. The investigations into the biological consequences of circadian disruption in women will offer insight into some menstrual-associated disorders, including mood changes, as well as reproductive function and possible links with breast cancer [4]. Many of the common features of PCOS, such as central obesity, hyperinsulinaemia and obstructive sleep apnoea, are associated with chronic sympathetic overactivity, suggesting that sympathoexcitation may be involved in the pathogenesis of this condition [5].

PCOS \& Sleep timing: The maturation of biological processes regulating sleep/wake systems, however, may be strongly related to the sleep timing and amount during adolescence-either as "compelling" or "permissive" factors. The two-process model of sleep regulation posits a fundamental sleep-wake homeostatic process (process S) working in concert with the circadian biological timing system (process $\mathrm{C}$ ) as the primary intrinsic regulatory factors [6]. How do these systems change during adolescence? However the changes are mediatedwhether through process $\mathrm{S}$, process $\mathrm{C}$, or by a combination many adolescents have too little sleep at the wrong circadian phase. This pattern is associated with increased risks for excessive sleepiness, difficulty with mood regulation, impaired academic performance, learning difficulties, school tardiness and absenteeism, and accidents and injuries [7]. However, the regulation of sleep is the only one aspect of the multitude of circadian rhythms in the body, and thus investigations of how general circadian disruption can affect the brain and body are essential. As such, the circadian clock finds itself at the center of a "web" of regulation impacting nearly every physiologic and behavioral system [8]. Therefore, disruption of this most central of regulatory systems is likely to have cascading effects throughout the organism, with potential knock-on effects on systems not directly controlled by the clock. In this study, we investigated the effect of sleep onset time and looked up in patients with polycystic ovary syndrome. Stress hormones, beta-End and melatonin are neurohormones that are involved in the sleep-wake cycle. Therefore, we investigated the pattern of time to sleep by sleep questionnaires and measure these hormones in women with polycystic ovary syndrome. Our recent research showed that $90 \%$ of these patients sleep late at night and sleep until noon [9]. Thus, the aims of the study were 1) to investigate whether there are differences in serum levels of stress hormones, beta-End and melatonin between women with and without PCOS; 2) to determine whether the sleep-wake pattern of women with PCOS is different from that of non-PCOS subjects; and 3) to determine the associations between these hormones and sleep quality in women with PCOS.

\section{Materials and Methods}

\subsection{Participants}

The participants included all women with PCO who visited Vali-e-Asr Clinic affiliated to Tehran University of Medical Sciences for the first time between February 2012 and 2013. The diagnosis of PCOS was made according to the joint criteria of the European Society of Human Reproduction and Embryology and the American Society of Reproductive Medicine (ESHRE/ASRM) [10]. In this study, 77 patients, aged 20 - 40 years participated who were not suffering from any illness except PCOS. Body mass index (BMI) was calculated as weight (kg)/height $(\mathrm{m})^{2}$. This study was approved in ethical committee of Tehran University of Medical Sciences. Demographic and sleep (PSQI) questionnaires were used in this study. Blood sample was obtained from all participants before 8AM.

\subsection{Clinical and Laboratory Investigation}

Concentration of serum levels of Adrenaline, Nor-adrenaline and Melatonin (Oxidized LDL Elisa), Beta-endorphin (ELISA kit, Cousabio from USA), Cortisol, progesterone (ELISA kit, Diametra from Italy) were measured by Eliza method at the Laboratory of Pathology of Vali-e-Asre. 


\subsection{Statistical Analysis}

Data was presented as mean \pm standard deviation also median if necessary. Qualitative variables were compared between control and PCO groups with chi square test. Normal distribution of quantitative variables was examined with kolmogorov-Smirnov test. The t-test was used to compare normal variables and Mann-Whitney test was used for variables without normal distribution. Pearson and Spearman correlation coefficient were used to evaluation relationship between hormones and PSQI score. This correlation evaluated closely according to a linear regression model. All analysis was done in SPSS 18 (SPSS Inc, Chicago Ill) Software. P-value less than 0.05 considered as significant level.

\section{Results}

In this study 77 woman in control group and 97 patients with PCO syndrome enrolled at infertility clinic of Valiasr Hospital, Tehran, Iran from February 2012 to 2013.

Results showed that women in control groups had more education than PCO group $(\mathrm{P}=0.003)$ (Table 1$)$. Irregular menstrual $(\mathrm{P}<0.001)$ and hirsutism $(\mathrm{P}<0.001)$ significantly were higher in women with $\mathrm{PCO}$.

According to Kolmogorov Smirniv melatonin, cortisol and beta-End showed a normal distribution, but adrenaline, noradrenaline and progesterone were not normally disturbed. Adrenalin level was higher in PCO group $(P<0.001)$. Serum levels of beta-End $(P=0.001)$ and melatonin $(P=0.031)$ were lower in women with PCO (Table 2).

Percentage of women that waking up morning before $7 \mathrm{am}(\mathrm{P}=0.408)$ and percentage of women that were sleeping more than 8 hours $(\mathrm{P}=0.660)$ were same in both groups (Table 3$)$.

In this analysis from all hormones only cortisol had significant relation with PSQI global score (P = 0.023). Determination coefficient of this model was weak and only 6.8 percentage (Table 4).

In PCO group mean of noradrenalin level in women that go to bed earlier were significantly higher than women that go to bed later $(\mathrm{P}=0.037)$. In PCO group noradrenalin level had not relation with waking up time $(\mathrm{P}=0.110)$ and sleep duration $(\mathrm{P}=0.510)$ (Table 5$)$.

Cortisol level of women in control group that waking up earlier was $158.51 \pm 81.02$ and it significantly lower than control group that waking up later $209.75 \pm 111 / 71$ ( $\mathrm{P}=0.018)$. Cortisol levels in the control group of women who sleep more than 8 hours was significantly less than women without 8 hours of sleep (Table 6).

\section{Discussion}

The results of this study showed that there is a relationship between neurohormones and sleep quality in women with PCOS. Recent studies have showed that, a reduced sleep duration and quality sleep can have an effect on

\begin{tabular}{|c|c|c|c|c|}
\hline & & $\begin{array}{l}\text { Control } \\
(\mathrm{n}=97)\end{array}$ & $\begin{array}{l}\text { PCOs } \\
(\mathrm{n}=77)\end{array}$ & $\begin{array}{l}\text { P-value } \\
\text { Chi square }\end{array}$ \\
\hline \multirow{2}{*}{ Education } & Primary or High school & $30(30.9 \%)$ & $41(53.2 \%)$ & \multirow{2}{*}{0.003} \\
\hline & Higher education & $67(69.1 \%)$ & $36(46.8 \%)$ & \\
\hline \multirow{2}{*}{ Occupation } & Occupied & $12(12.4 \%)$ & 7 (9.1\%) & \multirow{2}{*}{0.491} \\
\hline & Housekeeper & $85(87.6 \%)$ & $70(90.9 \%)$ & \\
\hline \multirow{2}{*}{ History of child bearing } & Yes & $25(25.8 \%)$ & 15 (19.5\%) & \multirow{2}{*}{0.327} \\
\hline & No & $72(74.2 \%)$ & $62(80.5 \%)$ & \\
\hline \multirow{2}{*}{ Abortion } & Yes & $11(11.3 \%)$ & $17(22.1 \%)$ & \multirow{2}{*}{0.056} \\
\hline & No & 86 (88.7\%) & 60 (77.9\%) & \\
\hline \multirow{2}{*}{ Obesity } & Yes & $53(54.6 \%)$ & $49(63.6 \%)$ & \multirow{2}{*}{0.231} \\
\hline & No & $44(45.4 \%)$ & $28(36.4 \%)$ & \\
\hline Age (Mean \pm SD) (year) & - & $29.6 \pm 5.2$ & $28.8 \pm 8.7$ & 0.076 \\
\hline Marital Duration (Mean \pm SD) (year) & - & $6.9 \pm 4.4$ & $7.0 \pm 4.1$ & 0.935 \\
\hline
\end{tabular}


Table 2. Comparison of age, PSQI scores and Hormones in study groups.

\begin{tabular}{|c|c|c|c|}
\hline & Control (N = 97) & PCOs $(\mathrm{N}=77)$ & P-value \\
\hline & Mean \pm SD & Mean \pm SD & t test \\
\hline Age (year) & $29.6 \pm 5.2$ & $26.6 \pm 4.7$ & $<0.001$ \\
\hline Marital Duration (year) & $6.9 \pm 4.4$ & $7.0 \pm 4.1$ & 0.935 \\
\hline \multicolumn{4}{|l|}{ PSQI Scores } \\
\hline Total Score (0 - 21) & $5.00 \pm 2.48$ & $5.16 \pm 2.33$ & 0.673 \\
\hline Sleep Quality (0 - 3) & $1.16 \pm 0.49$ & $1.10 \pm 0.58$ & 0.253 \\
\hline Sleep onset latency (0 - 3) & $1.65 \pm 1.18$ & $1.78 \pm 1.13$ & 0.455 \\
\hline Sleep duration (0 - 3) & $0.19 \pm 0.53$ & $0.25 \pm 0.67$ & 0.796 \\
\hline Sleep efficacy $(0$ - 3) & $0.09 \pm 0.38$ & $0.12 \pm 0.40$ & 0.641 \\
\hline Sleep disturbance (0 - 3) & $0.93 \pm 0.39$ & $0.97 \pm 0.36$ & 0.419 \\
\hline Using sleeping medication (0 - 3) & $0.13 \pm 0.61$ & $0.04 \pm 0.34$ & 0.169 \\
\hline Daytime dysfunction (0 - 3) & $0.85 \pm 0.80$ & $0.90 \pm 0.80$ & 0.679 \\
\hline \multicolumn{4}{|l|}{ Hormones } \\
\hline Melatonin (pg/ml) & $32.45 \pm 24.27$ & $25.48 \pm 15.99$ & 0.031 \\
\hline Cortisol (ng/ml) & $197.08 \pm 106.89$ & $190.57 \pm 75.07$ & 0.652 \\
\hline$\beta$-endorphin (pg/ml) & $87.19 \pm 9.39$ & $81.58 \pm 10.19$ & $<0.001$ \\
\hline Hormones & Mean \pm SD (Median) & Mean \pm SD (Median) & $\begin{array}{c}\text { P-value } \\
\text { Mann-Whitney }\end{array}$ \\
\hline Progesterone (mg/ml) & $3.79 \pm 7.73(0.80)$ & $2.22 \pm 3.24(0.80)$ & 0.982 \\
\hline Adrenalin (ng/ml) & $3.61 \pm 3.11(3.10)$ & $5.97 \pm 4.49(5.00)$ & $<0.001$ \\
\hline Noradrenalin (ng/ml) & $0.74 \pm 3.38(0.00)$ & $0.50 \pm 1.35(0.00)$ & 0.737 \\
\hline
\end{tabular}

Table 3. Comparison of sleep quality in study groups.

\begin{tabular}{|c|c|c|c|c|}
\hline & & $\begin{array}{l}\text { Control } \\
(N=97)\end{array}$ & $\begin{array}{c}\text { PCOs } \\
(\mathbf{N}=77)\end{array}$ & $\begin{array}{c}\text { P-value } \\
\text { Chi square }\end{array}$ \\
\hline \multirow{2}{*}{ Sleep Quality } & Good & $43(44.3 \%)$ & 33 (42.9\%) & \multirow{2}{*}{0.846} \\
\hline & Poor & 54 (55.7\%) & $44(57.1 \%)$ & \\
\hline \multirow{2}{*}{ Time of going to bed } & $\leq 23$ & 15 (15.5\%) & $14(18.2 \%)$ & \multirow{2}{*}{0.633} \\
\hline & $>23$ & 82 (84.5\%) & 63 (81.8\%) & \\
\hline \multirow{2}{*}{ Getting up time } & $\leq 7$ & 24 (24.7\%) & 15 (19.5\%) & \multirow{2}{*}{0.408} \\
\hline & $>7$ & $73(75.3 \%)$ & 62 (80.5\%) & \\
\hline \multirow{2}{*}{ Actual sleep duration } & $\leq 8$ hours & 32 (33.0\%) & 23 (29.9\%) & \multirow{2}{*}{0.660} \\
\hline & $>8$ hours & $65(67.0 \%)$ & 54 (70.1\%) & \\
\hline
\end{tabular}

Table 4. Regression coefficient of hormones on PSQI scores.

\begin{tabular}{|c|c|c|c|c|}
\hline & Regression Coefficient B & St. Error of B & t value & P-value \\
\hline Constant & 6.730 & 1.645 & 4.091 & 0.000 \\
\hline Progesterone (mg/ml) & -0.038 & 0.030 & -1.263 & 0.208 \\
\hline Adrenalin (ng/ml) & 0.055 & 0.046 & 1.205 & 0.230 \\
\hline Noradrenalin (ng/ml) & 0.051 & 0.069 & 0.743 & 0.458 \\
\hline Melatonin (pg/ml) & 0.010 & 0.009 & 1.148 & 0.253 \\
\hline Cortisol (ng/ml) & -0.005 & 0.002 & -2.287 & 0.023 \\
\hline$\beta$-endorphin (pg/ml) & -0.015 & 0.018 & -0.808 & 0.420 \\
\hline
\end{tabular}


Table 5. Adrenalin and Noradrenalin in different time of going to bed.

\begin{tabular}{cccccc}
\hline \multirow{2}{*}{ Hormones } & Time of going to bed & Control $(\mathbf{N}=\mathbf{9 7})$ & \multicolumn{2}{c}{ PCOs $(\mathbf{N}=\mathbf{7 7})$} \\
\cline { 3 - 6 } & & Mean \pm SD (Median) & P-value & Mean \pm SD (Median) & P-value \\
\hline Adrenalin & $\leq 23$ & $3.99 \pm 3.86(23.80)$ & 0.791 & $3.88 \pm 2.54(3.30)$ & 0.041 \\
$(\mathrm{ng} / \mathrm{ml})$ & $>23$ & $3.54 \pm 2.97(3.20)$ & & $6.43 \pm 4.71(5.40)$ & \\
Noradrenalin & $\leq 23$ & $0.10 \pm 0.26(0.0)$ & & $0.0 \pm 0.0(0.0)$ & 0.037 \\
$(\mathrm{ng} / \mathrm{ml})$ & $>23$ & $0.86 \pm 3.66(0.0)$ & & $0.61 \pm 1.47(0.0)$ & \\
\hline
\end{tabular}

Table 6. Cortisol and sleep time.

\begin{tabular}{ccccc}
\hline & & Control (N = 97) & & PCOs (N = 77) \\
\cline { 3 - 5 } & & Mean \pm SD (Median) & P-value & Mean \pm SD (Median) \\
\hline \multirow{2}{*}{ Getting up time } & $\leq 7$ & $158.51 \pm 81.02(134.2)$ & 0.018 & $194.61 \pm 112.87(148.6)$ \\
& $>7$ & $209.75 \pm 111.71(184.0)$ & $189.60 \pm 63.97(193.7)$ & $201.41 \pm 98.13(210.7)$ \\
Actual sleep & $\leq 8$ hours & $156.57 \pm 81.63(133.2)$ & 0.003 & $185.96 \pm 63.34(170.6)$ \\
\hline duration & $>8$ hours & $217.02 \pm 112.64(191.6)$ & & 0.412 \\
\hline
\end{tabular}

HPA axis activity. Last studies show that the early morning rise of ACTH and cortisol is reduced when additional energy is provided. This finding supports the view that the nocturnal rise in HPA axis activity contributes to preparing the organism for the upcoming wake period and associated increased energy demands [11]. Awakening is associated with a profound and global increase in the activation of neocortical networks mediated mainly by the brain stem arousing systems. Shortly after awakening, a sharp 38\% - 75\% (average 50\%) increase occurs in the blood level of cortisol in about 77\% of healthy adults [12] and it occurs in people of all ages [13]. Cortisol awakening response (CAR) provides an easy measure of the reactivity capacity of the HPA axis [14]. Notably, CAR has been found to be abolished in patients with memory disorders due to damage in the frontal lobes or the hippocampal region [15]. The "booting" of memory representations in the process of awakening presumably brings to preconsciousness and even consciousness the most relevant internal (e.g. self-concept related) and external (e.g. orientation in time and space, current life conditions) information that potentially stimulate HPA axis activity. This might explain why subjects with work overload, chronic worrying, social stress; loneliness or health problems were reported to show an altered CAR [16]. The "booting” of memory representations in the process of awakening presumably brings to preconsciousness and even consciousness the most relevant internal (e.g. self-concept related) and external (e.g. orientation in time and space, current life conditions) information that potentially stimulate HPA axis activity. This might explain why subjects with work overload, chronic worrying, social stress; loneliness or health problems were reported to show an altered CAR [17]. All of these reports show that, cortisol, noradrenaline, beta-End and melatoninare are very important in the process of awakening. The study of Prelević in 1993 showed, the 24-h blood cortisol profile pattern was significantly different in women with PCOS as compared to the controls. Significantly lower cortisol levels were observed during the night (levels were determined between 20.00 and 04.00 [18]. Molecular mechanisms underlying pathophysiology of PCOS, especially those related to cortisol signaling are poorly understood. In women with the polycystic ovary syndrome (PCOS), cortisol production rate is probably normal, although adrenal androgens can be overproduced in a subset of affected women [19]. Milutinovic's hypothesize in 2011 is that modulation of glucocorticoid receptor (GR) expression and function may underlie possible PCOS-related impairment of feedback inhibition of HPA axis activity and imply that PCOS is associated with increased GR protein concentration and HPA axis sensitivity to dexamethasone [20]. Then up-regulation of GR can be the reason of normal rate of cortisol in women with PCO. In this study our results showed that only cortisol has significant relation with PSQI global score by regression analysis. Cortisol level of control group that waking up earlier was significantly lower than control group that waking up later. Also cortisol level in control group on women with more than 8 hours sleep is significantly lower than women without 8 hours sleep. This data showed that a good night's sleep will reduce stress hormone. One possible candidate that likely contributes to the awakening response is the adrenergic locus coeruleus (LC) which is strongly activated at the transition to wakefulness [21]. It projects to the paraventricular nucleus, i.e., the major hypothalamic regulator of HPA axis activity. Noradrenergic activa- 
tion of the whole forebrain during awakening might feedback to the hypothalamic centers of pituitary-adrenal control [22]. This study showed that adrenalin level was higher in PCO group, whereas serum levels of bet-End and melatonin were lower and had not correlation with sleep quality. The levels of adrenaline and noradrenaline in patients with early sleep are much lower than patients who slept later. Notably, recent decades studies show that ACTH may be engaged in the up-regulation of gene expression of noradrenaline biosynthetic enzymes in sympathetic ganglia without the involvement of adrenal glucocorticoids because ACTH and related compounds have pharmacological potential for regulating the cardiovascular system by controlling noradrenaline biosynthesis in the superior cervical ganglia (SCG) and in the LC [23]. The LC is densely innervated by processes exhibiting endogenous opioid peptides [24] and contains a high concentration of $\mu$-opioid receptors ( $\mu \mathrm{OR})$ [25]. The interaction of beta-End with the HPA axis exerts a tonic inhibitory effect on sympathetic nervous system [26], the gonadotropin-releasing hormone $(\mathrm{GnRH})$ pulse generator and on pituitary luteinizing (LH) release [27]. These results showed that the feedback controls in brain-ovary axis in women with PCOS is different with nonPCOS. Our data suggest that the morning cortisol response is influenced by the awakening time. Appropriate regulatory control of the HPA axis is critical for health and survival; therefore time to sleep and wake-up time may have important roles in managing PCOS. Finally, we have two suggestions: 1) We suggest further study of $\mathrm{CRH}$ and CAR in order to reach a better knowledge about PCOS etiology and 2) Future research about sleep in PCO women should register other sleep dimensions (sleep patterns or disturbances) to provide a better insight in this scientific field.

\section{Conclusion}

In this study we investigated the relationship between the time to sleep and serum levels of neurohormones in women with PCO. Our results showed that only cortisol has significant relation with PSQI global score by regression analysis and it associated with time of sleep. Studies in recent decades have shown that lifestyle intervention improves body composition and so modifying sleep patterns in these patients may be able to regulate the hormonal balance in the brain-ovary axis.

\section{Acknowledgements}

This work was supported by the Research Council of Tehran University of Medical Sciences, Tehran, Iran.

\section{Conflict of Interests}

There is no conflict of interest among the authors.

\section{References}

[1] Norman, R.J., Dewailly, D., Legro, R.S. and Hickey, T.E. (2007) Polycystic Ovary Syndrome. The Lancet, 370, 685697. http://dx.doi.org/10.1016/S0140-6736(07)61345-2

[2] Badawy, A. and Elnashar, A. (2011) Treatment Options for Polycystic Ovary Syndrome. International Journal of Women's Health, 3, 25-35. http://dx.doi.org/10.2147/IJWH.S11304

[3] Yen, S.S.C. (1999) The Human Menstrual Cycle: Neuroendocrine Regulation. In: Yen, S.S.C., Jaffe, R.B. and Barbieri, R.L., Eds., Reproductive Endocrinology: Physiology, Pathophysiology, and Clinical Management, W.B. Saunders Co., Philadelphia, 191-217.

[4] Baker, F.C. and Driver, H.S. (2007) Circadian Rhythms Sleep and the Menstrual Cycle. Sleep Medicine, 8, 613-622. http://dx.doi.org/10.1016/j.sleep.2006.09.011

[5] Lansdown, A. and Rees, D.A. (2012) The Sympathetic Nervous System in Polycystic Ovary Syndrome: A Novel Therapeutic Target? Clinical Endocrinology (Oxford), 77, 791-801. http://dx.doi.org/10.1111/cen.12003

[6] Borbely, A.A. (1982) A Two Process Model of Sleep Regulation. Human Neurobiology, 1, 195-204.

[7] Carskadon, M.A., Acebo, C. and Jenni, O.G. (2004) Regulation of Adolescent Sleep: Implications for Behavior. Annals of the New York Academy of Sciences, 1021, 276-291. http://dx.doi.org/10.1196/annals.1308.032

[8] Karatsoreos, I.N., Bhagat, S., Bloss, E.B., Morrison, J.H. and McEwen, B.S. (2011) Disruption of Circadian Clocks Has Ramifications for Metabolism, Brain, and Behavior. Proceedings of the National Academy of Sciences of the United States of America, 108, 1657-1662. http://dx.doi.org/10.1073/pnas.1018375108

[9] Zangeneh, F.Z., Naghizade, M.M., Abedinia, N., Haghollahi, F. and Hezarehei, D. (2012) Psychological Signs in Pa- 
tients with Polycystic Ovary Syndrome. Journal of Family and Reproductive Health, 6, 145-151.

[10] Rotterdam ESHRE/ASRM-Sponsored PCOS Consensus Workshop Group (2004) Revised 2003 Consensus on Diagnostic Criteria and Long-Term Health Risks Related to Polycystic Ovary Syndrome (PCOS). Human Reproduction, 19, 41-47.

[11] Born, J., Hansen, K., Marshall, L., Molle, M. and Fehm, H.L. (1999) Timing the End of Nocturnal Sleep. Nature, 397, 29-30.

[12] Wüst, S., Wolf, J., Hellhammer, D.H., Federenko, I., Schommer, N. and Kirschbaum, C. (2000) The Cortisol Awakening Response-Normal Values and Confounds. Noise Health, 2, 79-88.

[13] Fries, E., Dettenborn, L. and Kirschbaum, C. (2009) The Cortisol Awakening Response (CAR): Facts and Future Directions. International Journal of Psychophysiology, 72, 67-73. http://dx.doi.org/10.1016/j.ijpsycho.2008.03.014

[14] Schmidt-Reinwald, A., Pruessner, J.C., Hellhammer, D.H., Federenko, I., Rohleder, N., Schürmeyer, T.H. and Kirschbaum, C. (1999) The Cortisol Response to Awakening in Relation to Different Challenge Tests and a 12-Hour Cortisol Rhythm. Life Sciences, 64, 1653-1660. http://dx.doi.org/10.1016/S0024-3205(99)00103-4

[15] Wolf, O.T., Fujiwara, E., Luwinski, G., Kirschbaum, C. and Markowitsch, H.J. (2005) No Morning Cortisol Response in Patients with Severe Global Amnesia. Psychoneuroendocrinology, 30, 101-105. http://dx.doi.org/10.1016/j.psyneuen.2004.05.001

[16] Kudielka, B.M. and Kirschbaum, C. (2003) Awakening Cortisol Responses Are Influenced by Health Status and Awakening Time but Not by Menstrual Cycle Phase. Psychoneuroendocrinology, 28, 35-47. http://dx.doi.org/10.1016/S0306-4530(02)00008-2

[17] Schlotz, W., Hellhammer, J., Schulz, P. and Stone, A.A. (2004) Perceived Work Overload and Chronic Worrying Predict Weekend-Weekday Differences in the Cortisol Awakening Response. Psychosomatic Medicine, 66, 207-214. http://dx.doi.org/10.1097/01.psy.0000116715.78238.56

[18] Prelević, G.M., Würzburger, M.I. and Balint-Perić, L. (1993) 24-Hour Serum Cortisol Profiles in Women with Polycystic Ovary Syndrome. Gynecological Endocrinology, 7, 179-184. http://dx.doi.org/10.3109/09513599309152500

[19] Pasquali, R. and Gambineri, A. (2012) Cortisol and the Polycystic Ovary Syndrome. Expert Review of Endocrinology \& Metabolism, 7, 555-566. http://dx.doi.org/10.1586/eem.12.42

[20] Milutinović, D.V., Macut, D., Božić, I., Nestorov, J., Damjanović, S. and Matić, G. (2011) Hypothalamic-PituitaryAdrenocortical Axis Hypersensitivity and Glucocorticoid Receptor Expression and Function in Women with Polycystic Ovary Syndrome. Experimental and Clinical Endocrinology \& Diabetes, 119, 636-643. http://dx.doi.org/10.1055/s-0031-1283122

[21] Hobson, J.A. and Pace-Schott, E.F. (2002) The Cognitive Neuroscience of Sleep: Neuronal Systems, Consciousness and Learning. Nature Reviews Neuroscience, 3, 679-693. http://dx.doi.org/10.1038/nrn915

[22] Berridge, C.W., Isaac, S.O. and Espana, R.A. (2003) Additive Wake-Promoting Actions of Medial Basal Forebrain Noradrenergic Alpha1- and Beta-Receptor Stimulation. Behavioral Neuroscience, 117, 350-359. http://dx.doi.org/10.1037/0735-7044.117.2.350

[23] Kawabe, T., Chitravanshi, V.C., Kawabe, K. and Sapru, H.N. (2006) Cardiovascular Effects of Adrenocorticotropin Microinjections into the Rostral Ventrolateral Medullary Pressor Area of the Rat. Brain Research, 1102, 117-126. http://dx.doi.org/10.1016/j.brainres.2006.05.002

[24] Reyes, B.A.S., Glaser, J.D., Magtoto, R. and Van Bockstaele, E.J. (2006) Pro-Opiomelanocortin Colocalizes with Corticotropin-Releasing Factor in Axon Terminals of the Noradrenergic Nucleus Locus Coeruleus. European Journal of Neuroscience, 23, 2067-2077. http://dx.doi.org/10.1111/j.1460-9568.2006.04744.x

[25] Mansour, A., Fox, C.A., Akil, H. and Watson, S.J. (1995) Opioid-Receptor mRNA Expression in the Rat CNS: Anatomical and Functional Implications. Trends in Neurosciences, 18, 22-29. http://dx.doi.org/10.1016/0166-2236(95)93946-U

[26] Zangeneh, F.Z., Mohammadi, A., Ejtemaeimehr, S.H., Naghizadeh, M.M. and Aminee, F. (2011) The Role of Opioid System and Its Interaction with Sympathetic Nervous System in the Processing of Polycystic Ovary Syndrome Modeling in Rat. Archives of Gynecology and Obstetrics, 283, 885-892. http://dx.doi.org/10.1007/s00404-010-1776-7

[27] Genazzani, A.R., Genazzani, A.D., Volpogni, C., Pianazzi, F., Li, G.A., Surico, N. and Petraglia, F. (1993) Opioid Control of Gonadotrophin Secretion in Humans. Human Reproduction, 8, 151-153. http://dx.doi.org/10.1093/humrep/8.suppl_2.151 
Scientific Research Publishing (SCIRP) is one of the largest Open Access journal publishers. It is currently publishing more than 200 open access, online, peer-reviewed journals covering a wide range of academic disciplines. SCIRP serves the worldwide academic communities and contributes to the progress and application of science with its publication.

Other selected journals from SCIRP are listed as below. Submit your manuscript to us via either submit@scirp.org or Online Submission Portal.
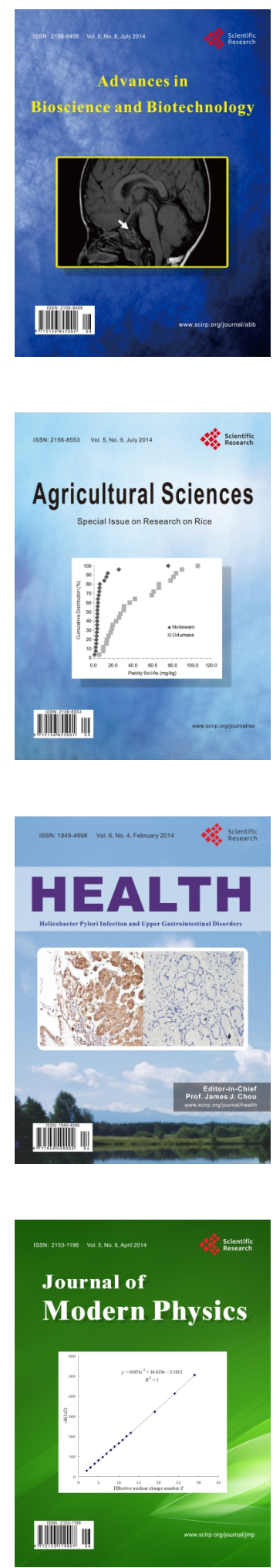
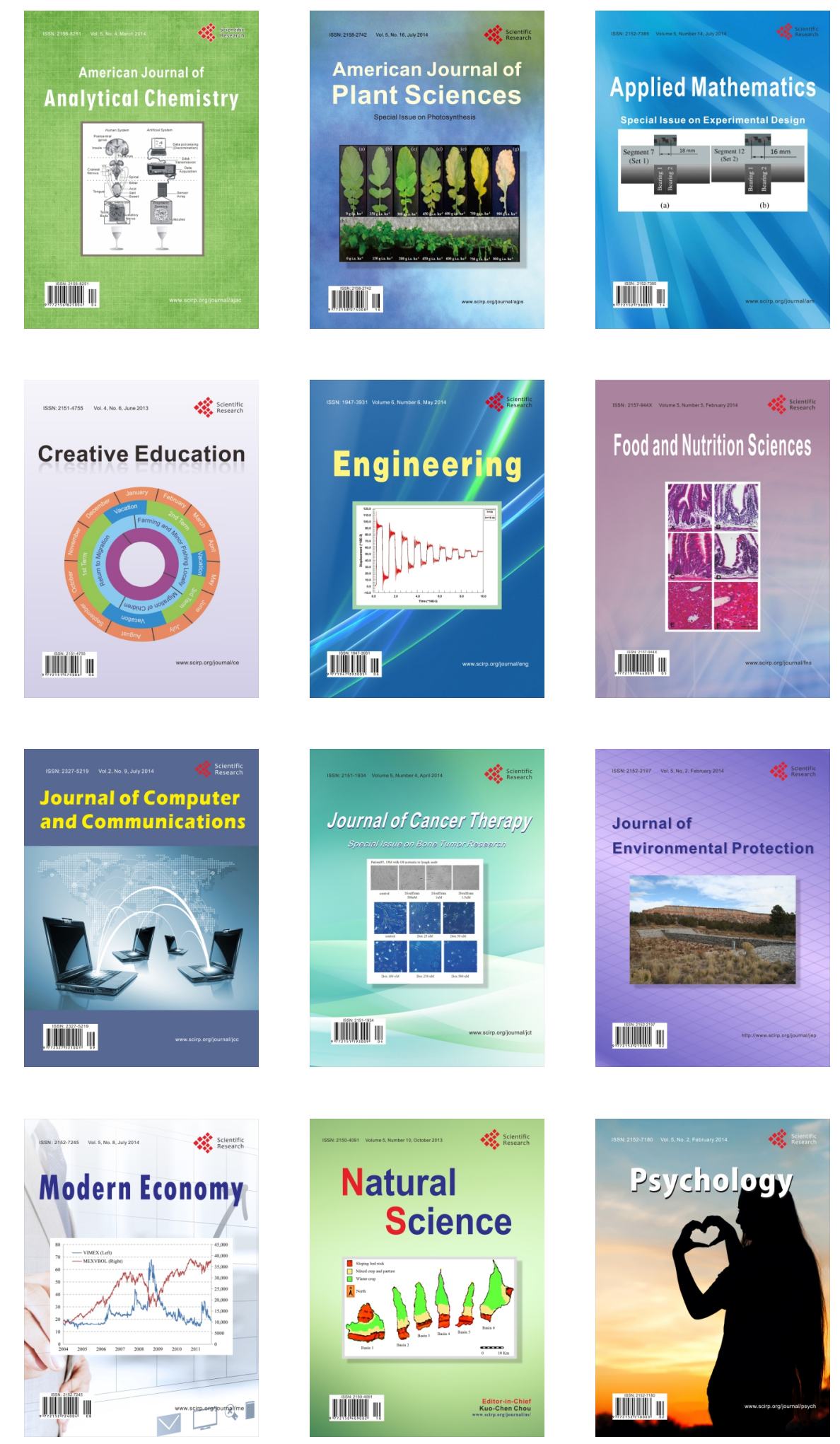